\title{
Nutrient budgets - a key indicator of soil sustainability
}

\author{
M.B. O'CONNOR', I.K. BODDY', J.D. MORTON' and D.C. EDMEADES' \\ ${ }^{1}$ AgResearch, Ruakura Research Centre, Private Bag 3123, Hamilton \\ ${ }^{2}$ AgResearch, Invermay Agricultural Centre, Private Bag 50034, Mosgiel
}

\section{Abstract}

Sustainable land management is now embedded in New Zealand law in the form of the Resource Management Act, 1991. Nutrient budgets and soil tests are seen as important tools for monitoring soil chemical sustainability. Nutrient budgets require that all inputs and outputs of nutrients from a farm are quantified. The aim is to ensure inputs and outputs are in balance thus producing a sustainable system. Recent experience suggests that using the study group (or Landcare group) approach is an effective way of introducing the nutrient budgeting approach to farmers. At the same time a computer software package ('Overseer') for assisting the calculations involved is being developed and tested. $\mathrm{P}$ nutrient budgets for two Waikato dairy farms suggest that surplus $\mathrm{P}$ is being produced. Such information provides a basis for future decisions on $\mathrm{P}$ fertiliser inputs to balance the $\mathrm{P}$ requirements for production against those for sustainable land management. Nutrient budgets can be aggregated to the regional and national level as required. By being able to calculate nutrient budgets in this way, New Zealand will be in a good position to demonstrate a commitment to nutrient management-thus ensuring continued and perhaps enhanced market access for our agricultural products.

Keywords: dairying, nutrient budgets, study groups, sustainable land management

\section{Introduction}

New Zealand's economy is largely an agricultural one, with more than two-thirds of our land area being used for-agriculture.-It-is therefore inevitable that agriculture's impact on the environment is significant. Sustainable Land Management is now embedded in New Zealand law in the form of the Resource Management Act (RMA), and the recent Sustainable Land Management strategy (MfE, 1996) is seen as a tool for making the RMA work in practice for landowners. Various terms have been used to describe sustainable land management as it relates to farming. "Producing quality products from a quality environment", "protecting the environment for future generations" and, importantly, "sustainability along with economic viability" have all been used in this context. Achieving these in practice will be a major challenge to farmers, consultants and scientists alike.

Development of soil quality indicators is being encouraged in order to monitor soil quality. Soil tests on farms have been used routinely for a number of years to measure soil chemical status. Nutrient budgets are seen as an extension of these tests and are rapidly becoming an important and internationally recognised indicator of sustainable land management.

\section{Nutrient budgets}

Nutrient budgets require that all inputs and outputs of nutrients from the farm are quantified. Nutrient inputs include fertiliser, feed supplements brought in, stocking rate, clover content ( $\mathrm{N}$-fixation), stock gains and slowrelease inputs from the soil. Outputs include nutrients contained in milk, meat and wool, in stock and pasture supplements sold, in stock transfer losses off the grazing area and in soil losses.

From the farmers' viewpoint it is better to consider nutrient budgeting as nutrient "balancing" where the aim is to balance the loss of a nutrient with inputs required to replace that loss and hence keep the system

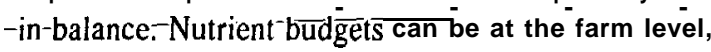
the regional level and the national level. All will be important in the future, but for the purpose of this paper we will confine ourselves to the farm level.

\section{0 verseas experience}

Nutrient budgets drawn up for intensive farming systems in Europe and the United States invariably show surpluses of phosphorus (P) (e.g., Haygarthetaf. 1996). In Ireland, soil $P$ tests have_increased_markedly over 'time (Figure 1) and a typical Irish dairy farm will indicate a surplus of $P$ (Table la, b). As a result the concept of nutrient management planning has been introduced, which on an individual farm basis involves intensive soil testing and matching the rate of nutrient application in fertiliser and slurry to the demand of the pasture or crop grown. In the US this has been taken a stage further by identifying and prioritising catchments that are vulnerable to pollution, setting of clear water quality goals and targeting the specific areas within a catchment which contribute to the problem (Daniel et al. 1996). 
Figure 1, Olsen $\mathrm{P}$ levels on lrish dairy farms over time (Tunney 1990).

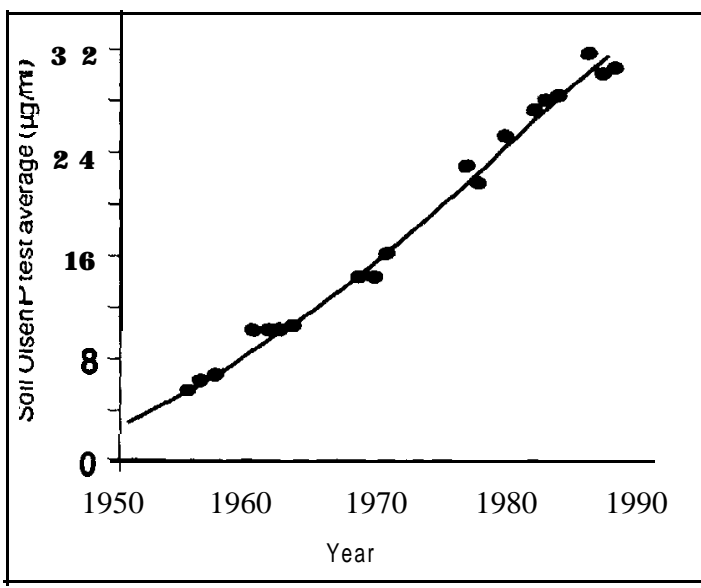

Table 1 (a) Typical Irish dairy farm.

- 40ha pasture

$2.5 \mathrm{cows} / \mathrm{ha}$

$350 \mathrm{~kg}$ milk solids/cow

4 months indoor feeding

$500 \mathrm{~kg}$ concentrate/cow

Olsen P 30

Table 1 (b) Phosphorus budget for a typical Irish dairy farm.

\begin{tabular}{lc}
\hline Gains & $\mathrm{kg} \mathrm{P} / \mathrm{ha}$ \\
\hline Fertiliser & 30 \\
Concentrate & 3 \\
Total & 33 \\
\hline Losses & \\
\hline Soil & 4 \\
Animal & 13 \\
Total & 17 \\
Surplus & 16 \\
\hline
\end{tabular}

Experience with nutrient budgeting in $\mathrm{New}$ Zealand - an on-farm dairy study group in the $W$ aikato

A study group approach to sustainable farming practices has been in operation in the Waikato for the past 18 months. The project aims to achieve acceptable standards of on-farm environmental management while maintaining farm viability. The dairy study group makeup is outlined in Table 2 . The group meets on a regular basis (4-5 times/year) with the meetings rotating around the farmers' properties.

The group agreed, after much discussion of the factors affecting sustainable land management, that
Table 2 Dairy study group, Waikato.

\begin{tabular}{ll}
\hline & 7 Farmers \\
& 3 AgResearch \\
& 1 Facilitator (consultant) \\
& 1 Environment Waikato Officer \\
\hline
\end{tabular}

nutrient budgeting (or balancing) should be given high priority. It also became apparent that for the system to be implemented the farmers themselves needed to understand and be part of the budgeting process. The first nutrient to be considered was $P$.

In considering the process of nutrient budgeting for $\mathrm{P}$, the farmer members were able to supply the following information for their farms:

- $P$ fertiliser inputs

the quantities of brought-in feed

milk production data

numbers of cull cows and other stock sold

the time animals were off the grazing area in the milking shed and races.

The Outlook ${ }^{\mathrm{rM}}$ model was then used to generate a nutrient budget for $P$ on the different farms in the group. $\mathrm{P}$ nutrient budgets for two farms are shown in Table 3.

Table $3 \quad \mathrm{P}$ nutrient budgets for two Waikato dairy farms.

\begin{tabular}{|c|c|c|c|c|}
\hline \multirow{2}{*}{$\begin{array}{l}\text { Farm } 1 \\
\text { ka P/ha }\end{array}$} & \multicolumn{4}{|c|}{ Year } \\
\hline & 1992 & 1993' & 1994 & 1995 \\
\hline P Inputs & 38 & 70 & 74 & 81 \\
\hline P outputs & 53 & 54 & 55 & 56 \\
\hline Balance & -15 & 16 & 19 & 25 \\
\hline Olsen P & 28 & & & $41(34)^{*}$ \\
\hline Farm 2 & \multicolumn{4}{|c|}{ Year } \\
\hline kg P/ha & 1992 & 1993 & 1994 & 1995 \\
\hline P Inputs & 53 & 53 & 53 & 48 \\
\hline P outputs & 37 & 38 & 39 & 39 \\
\hline Balance & 16 & 15 & 14 & 9 \\
\hline Olsen P & 26 & & & $28(30)^{*}$ \\
\hline
\end{tabular}

* Olsen P calculated

For both farms $\mathrm{P}$ inputs exceeded $\mathrm{P}$ outputs and this was reflected in an increase in Olsen $P$ values (Table 3). Such information provides a good basis for future decisions on $\mathrm{P}$ fertiliser inputs and allows one to balance the $P$ requirements for production against those for sustainable land management. Obviously increases in soil $P$ levels above the optimum for maximising farm production are wasteful and likely to lead to environmental problems.

Comparison of these two farms with the Irish situation suggests similarities in the surplus $\mathrm{P}$ generated. 
Other information (Roberts et al. 1996) supports a general trend to increasing soil $P$ status on New Zealand dairy farms and highlights the need for balance between production and environmental needs.

\section{Value of the study group approach}

The study group approach is seen as an effective way of achieving changes in land use practices. The Waikato experience has shown that the group approach of having farmers, scientists and environmentalists meeting in a small group to discuss a topic like nutrient budgeting is a very successful and rewarding experience to all concerned. Farmers learn about the value of nutrient budgets and their relationship with fertiliser recommendations, the process of budgeting is collectively demonstrated and its value and wider implications are dealt with. Likewise, other group members become aware of the farmers concerns and the interpretations they place on advice given. The information gained in the small groups can then be extended to the wider community through field-days, seminars and conferences like that of the NZGA.

\section{Computer-based software for calculating nutrient budgets}

AgResearch, in conjunction with MAF Policy, have produced a stand-alone software programme (Overseer) for calculating nutrient budgets.

The software currently looks at the four major fertiliser nutrients (phosphorus, sulphur, potassium and nitrogen) but, has been developed-in-a-manner--that-would allow expansion to cover other nutrients, both macro and trace. For $P$ and $S$ these functions are based on those in the Outlook" model (Metherell et al. 1995), with the $\mathrm{K}$ equation based on the research of Cornforth \& Sinclair (1982) and those for $N$ supplied by S.F. Ledgard (pers. comm). The $\mathrm{K}$ and $\mathrm{N}$ models will be updated as further research becomes available.

The Overseer software program works best for the calculation of nutrient budgets for individual farms. However, there is a growing need to produce nutrient budgets on a regional and-national-level. There-are two options available: (1) the use of average regional data or (2) the aggregation of individual farm data. There are problems with the former option as it relies on statistical sources. Ideally, if sufficient farmers were calculating individual nutrient budgets, option (2) would be preferred. Information could be stored (anonymously) in a central data base by region, farm type, soil type, etc. This would then facilitate the process of reporting on New Zealand's nutrient status to international organisations such as OECD.

\section{Conclusions}

Nutrient budgeting is clearly becoming an important and internationally recognised indicator of sustainable land management. To assist in the process of nutrient budgeting, AgResearch has developed dynamic nutrient models for $P$ and $S$ and is currently researching $K$ and $N$ models for this purpose. Software packages have also been developed for compiling nutrient budgets and these, together with helpful inputs from agribusiness clients, e.g., fertiliser purchases are being converted to nutrient inputs ( $\mathrm{T}$. Johnston, BOP Fertiliser Ltd, pers. comm.), which will all assist in the compilation of nutrient budgets for the farm, the region and national situation.

We strongly suggest that the process of nutrient budgeting and the alteration of nutrient inputs to make the land sustainable needs to be done in a participatory manner and not a regulatory manner. We believe such an approach can be accomplished through study group or Landcare group participation followed by extension to the wider community. In this regard we applaud recent Government initiatives for setting-up Landcare Trusts and Landcare groups in New Zealand for the promotion of sustainable land management.

For New Zealand to maintain and we hope enhance its access to international markets, it is essential that we are able to demonstrate a commitment to nutrient management in the agricultural sector. By being able to calculate nutrient budgets at a farm level and aggregate these to the regional and national level, New Zealand will be in a position to demonstrate such a commitment to its international trading partners, thus ensuring -continued-market access for ${ }^{-i t}$ agricultural products.

\section{ACKNOWLEDGEMENTS}

We are grateful to Paul Marshall and Phil Journeaux for software development and support and to Liz Wedderburn and lan Tarbotton for use of study group information.

\section{REFERENCES}

Cornforth, I.S.; Sinclair;-A.G. 1982. Fertiliser recommendations for pastures and crops in New Zealand. 2nd ed. New Zealand Ministry of Agriculture and Fisheries. pp. 18-19.

Daniel, T.; Carton, 0.; Magette, W. 1996. Nutrient management planning. pp. 279-299.In: Phosphorus losses from soil to water. London: $C A B$ International.

Haygarth, P.M.: Jarvis. S.C.; Chapman, P.J.; Smith P.V. 1996. Mass balances of phosphorus in grassland systems. Soil use and management (in press). 
Metherell, A.K.; McCall, D.G.; Woodward, S.J.R. 1995. Outlook: a phosphorus fertiliser decision support model for grazed pastures. pp. 24-39. In: Currie, L.D. and Logananthan, P. (eds). Fertiliser requirements of grazed pasture and field crops: Macro- andmicro-nutrients. Occasional Report No. 8. Fertiliser and Lime Research Centre, Massey University, Palmerston North, New Zealand.

Ministry for the Environment. 1996. Sustainable Land Management. A strategy for New Zealand. Wellington: Ministry for the Environment.
Roberts, A.H.C.; Morton, J.D.; O'Connor, M.B; Edmeades, DC. 1996. Building a solid foundation for pasture production in Northland: P, K, S and lime requirements.Proceedings of the New Zealand Grassland Association 57: 119-l 2.5.

Tunney, K. 1990. A note on a balance sheet approach to estimating the phosphorus fertiliser needs of agriculture. Irish journal of agricultural research 29: $149-154$. 